\title{
Characteristics of Low-level Jets in Shanghai during the 2008-2009 Warm Seasons as Inferred from Wind Profiler Radar Data
}

\author{
Yu DU, Qinghong ZHANG, Yue YING \\ Laboratory for Climate and Ocean-Atmosphere Studies, Department of Atmospheric and Oceanic Sciences, \\ School of Physics, Peking University, Beijing, China \\ and \\ Yinming YANG \\ Shanghai Meteorological Bureau, Shanghai, China
}

(Manuscript received 8 October 2011, in final form 18 August 2012)

\begin{abstract}
In order to understand the characteristics of low-level jets (LLJs) over coastal areas of China Continent and its linkages with rainfall during the warm seasons, half-hourly data from a wind profiler radar (WPR) at the Qingpu site during the Meiyu periods of 2008 and 2009 in addition to data from one month prior to and after (non-Meiyu periods) were used to develop a climatology of the LLJs over Shanghai, China. Two peaks in LLJ incidence were revealed at 500-800 m and 2100-2200 m altitudes. Thus, we classified the observed LLJs into two types: (1) boundary-layer jets (BLJs, below $1 \mathrm{~km}$ ) and (2) synoptic-system-related LLJs (SLLJs, within 1-3 $\mathrm{km}$ ). BLJS and SLJs showed different behavior in their temporal variation of the occurrence frequency, wind direction, and relation to rainfall. The BLJs displayed a more evident diurnal cycle than the SLLJs, with maximum incidence occurring in nighttime and early morning. The SLLJs occurred more frequently during Meiyu periods than non-Meiyu periods, whereas the occurrence frequency of BLJs increased throughout the warm seasons with no peak during Meiyu periods. BLJs are mostly southerly winds that might be induced by inertial oscillation with a strong background southerly geostrophic wind due to the west-east land-ocean thermal difference. SLLJs most frequently appeared as southwesterly and westerly winds embedded in the East Asian monsoon circulation. The relation between LLJS and precipitation was examined by comparing the frequency of LLJs occurrence on rainy days (cases), with daily (4-hourly) accumulated rainfall within 1 to $10 \mathrm{~mm}$, and non-rainy days (cases) because the missing rate of WPR data is high during heavy rainfall events. Both BLJS and SLLJs occur more often on rainy days than on non-rainy days. In shorter time scales (4 hours), both BLJs and SLLJs tend to occur frequently during, before and after rainy cases, except SLLJs before rainy cases.
\end{abstract}

Corresponding author: Qinghong Zhang, Department of Atmospheric and Oceanic Sciences, School of Physics, Peking University, Beijing 100871, China.

E-mail: qzhang@pku.edu.cn

(C)2012, Meteorological Society of Japan

\section{Introduction}

Low-level jets (LLJs) are defined as horizontal wind speed maxima in the lowest few kilometers of the troposphere (e.g., Stensrud 1996). LLJs are observed in many parts of the world. Their occurrence is often associated with the development and evolution of deep 
convective precipitation. The characteristics of LLJs have been widely documented in observational studies (Chen et al. 1994; Frisch et al. 1992; Lothon et al. 2008; Parish et al. 1988), numerical simulations (Chou et al. 1990; Jiang et al. 2007; Kato 1998; Parish and Oolman 2010; Werth et al. 2011; Zhong et al. 1996), and theoretical analyses (Blackadar 1957; Holton 1967; Van de Wiel et al. 2010).

The formation mechanisms of LLJs varied in previous studies, depending on the location of LLJs. The formation mechanisms could be classified into two types. The first is more related to local diurnal oscillations, such as inertial oscillations (Blackadar 1957; Van de Wiel et al. 2010), shallow baroclinicity produced by sloping terrain (Holton 1967) or by land-sea thermal contrast over the coastal regions and orographic blocking ( $\mathrm{Li}$ and Chen 1998; Lin et al. 2011). The second type is more coupled with synoptic or sub-synoptic-scale weather systems, such as isallobaric forcing (Uccellini and Johnson 1979), baroclinicity from the development of extratropical cyclones (Djuric and Damiani 1980; Newton 1967), and diabatic effects (Uccellini et al. 1987).

Given the different LLJ formation mechanisms, more detailed terminology should be coined to distinguish LLJs. In this paper, we classify LLJs into two types following Chen et al. (1994): (1) boundary layer jets (BLJs), which occur in the planetary boundary layer with significant vertical shear of horizontal wind and significant diurnal variation; and (2) synoptic-system-related LLJs (SLLJs, as LLJs defined by Chen et al. 1994), which occur in the 600 to $900 \mathrm{hPa}$ layer and are usually related to synoptic-scale weather systems.

Previous studies of LLJs over East Asia tended to focus on the relationship of LLJs to heavy precipitation during Meiyu periods (Chen and Yu 1988; Matsumoto et al. 1971; Ninomiya and Murakami 1987; Tao and Chen 1987). A few also discussed climatological characteristics (Chen et al. 2005; Pham et al. 2008) compared to those in the United States (Bonner 1968; Karipot et al. 2009; Mitchell et al. 1995; Song et al. 2005; Whiteman et al. 1997). In these studies (Chen and Yu 1988; Matsumoto et al. 1971; Ninomiya and Murakami 1987; Tao and Chen 1987), LLJs over East Asia were defined as narrow horizontal zones of highspeed flow along the south side of the Meiyu fronts. The role LLJs play in transporting warm and moist air northward has received much interest. These LLJs are coupled to the East Asia monsoon and closely related to the Meiyu fronts. They hence fall into the SLLJs category. Compared to SLLJs, BLJs over East Asia are less documented. Rife et al. (2010) reported the diurnal variation in LLJs over China at a 450-m height level from their 1985-2005 global downscaled reanalysis. Pham et al. (2008) identified the diurnal variation in LLJs over Okinawa, southern part of Japan (see Fig. 1), from hourly wind profiler radar (WPR) data. These studies provided evidence of the incidence of BLJs (LLJs with obvious diurnal variations in boundary layer) over East Asia.

So far, our understanding of East Asia LLJs is insufficient due to a lack of detailed SLLJs and BLJS charecteristics. Moreover, the LLJs at different locations over East Asia may not have the same characteristics. Chen et al. (2005) statistically classified LLJs over Taiwan into different types by their height, appearance (single jet or double jet), and movement (migratory and non-migratory) through the use of 12-hour sounding data. Unfortunately, the low-temporal-resolution observations they used might miss detailed LLJs behavior, such as the diurnal cycle. Compared with conventional observation, WPR data have much higher temporal resolution. Thus, we believe that long-term WPR data are suitable for identifying the statistical characteristics of LLJs (Pham et al. 2008). Pham et al. (2008) reported an interesting aspect of the LLJ over Okinawa, but did not study BLJs and SLLJs separately over Okinawa. Differences between BLJs and SLLJs in various locations over East Asia need to be further evaluated.

In this paper, we used high temporal and vertical resolution 1289-MHz WPR data at the Qingpu site (located in Shanghai, China, see Fig. 1) to gather WPR data of high temporal and vertical resolution. On the basis of these high-resolution data, we documented and evaluated the statistical characteristics of LLJs (including SLLJs and BLJs) in Shanghai during the 2008-2009 warm seasons (pre-Meiyu, Meiyu, and post-Meiyu periods). The Meiyu period (Baiu period in Japan) is an early-summer rainy season in subtropical China and Japan when extremely heavy rainfall is one of the most significant weather phenomena (Tao and Chen 1987). The main objective in this study is to clarify the difference in statistical characteristics between BLJs and SLLJs in Shanghai and provide statistical evidence for their formation mechanisms. In Section 2, we present the data and statistical methods used. The vertical distribution of LLJ occurrence frequency is shown in Section 3 to classify the LLJs into two types. In Section 4 , we present the observed characteristics of both types of LLJ, including their temporal variation of the occurrence frequency, horizontal wind direction, and relationship with warm-season precipitation. In Section 5 , we also describe the relationship between BLJs 
and SLLJs through the characteristics of double LLJs (simultaneous occurrence of BLJs and SLLJs). From statistical results combined with previous theories, possible formation mechanisms for the BLJs and SLLJs are discussed in Section 6. The final section summarizes our results.

\section{Data and methodology}

\section{$2.1 \quad$ Data}

The 1289-MHz WPR installed at the Qingpu site $\left(31.1^{\circ} \mathrm{N}, 121.1^{\circ} \mathrm{E}\right)$ in Shanghai (Fig. 1) can operate in low-power and high-power modes, which have vertical scanning ranges of 187-1109 $\mathrm{m}$ and 854-3005 $\mathrm{m}$ respectively, with intervals of $100 \mathrm{~m}$. The temporal resolution for both modes is $30 \mathrm{~min}$. Vertical scanning data in each mode are combined to produce vertical wind profiles from $187 \mathrm{~m}$ to $3005 \mathrm{~m}$ every 30 minutes. For the scanning overlap part of the two modes, the low-power mode data are removed because they have a higher missing rate $(6.36 \%)$ than the high-power mode data $(0.73 \%)$. The high vertical resolution and coverage allow us to capture the peaks at different heights related to the LLJs.

The WPR data were checked for availability and quality before statistics were compiled. We checked the data duration and missing rate. The 2-year record was continuously stored during warm seasons (Meiyu, pre-Meiyu, and post-Meiyu periods) from 2008 to 2009. The Meiyu periods in Shanghai were from 7 June to 3 July in 2008 and from 20 June to 8 July in 2009 according to the Shanghai Water Authority. In this study, the pre-Meiyu (post-Meiyu) period was treated as one month before (after) the corresponding Meiyu period. The missing rate (ratio of missing profiles to the total number of profiles) was $9.37 \%$ during the study periods, which is similar to the rate reported by Pham et al. (2008). Figure 2 shows a time-height Hovmöller diagram of the data missing rate. The missing rate below $500 \mathrm{~m}$ is lower than that found by Pham et al. (2008). A relatively higher data missing rate was found in the early morning and late afternoon.

In addition to the WPR data, we also used National Centers for Environmental Prediction (NCEP) Final (FNL) Operational Global Analysis data on a $1.0 \mathrm{x}$ 1.0 degree grid every 6 hours over the same period to provide the corresponding environmental conditions associated with the LLJs. The zonal temperature anomaly is defined as the difference between the zonal mean temperature (average from $111^{\circ} \mathrm{E}$ to $133^{\circ} \mathrm{E}$ ) and the mean temperature during the warm seasons. Additionally, hourly accumulated precipitation data were collected from an automatic weather station at the

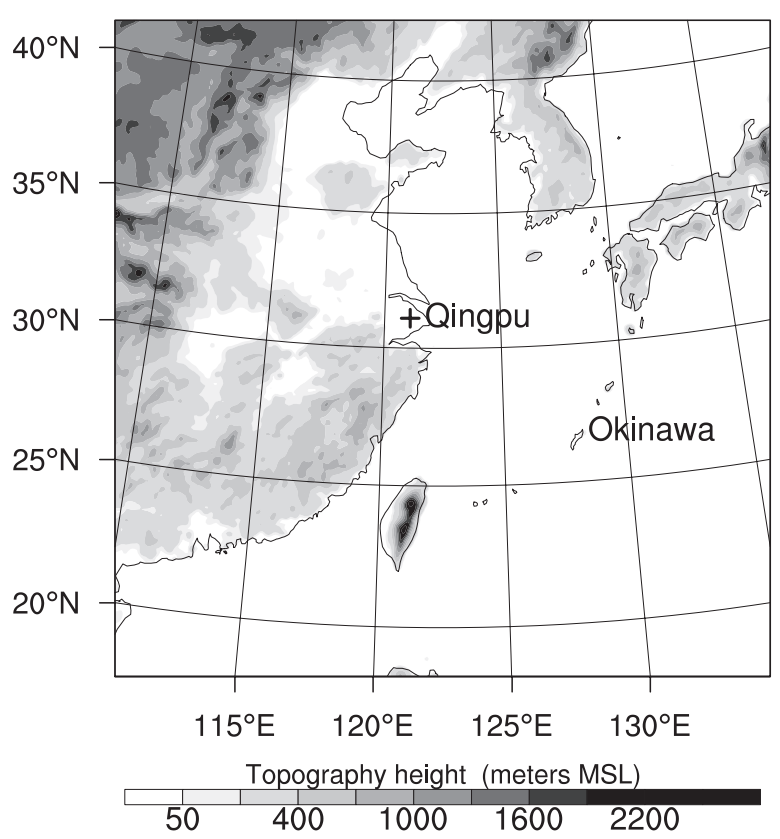

Fig. 1. Location of the Qingpu site and Okinawa. Shadings represent terrain Height.

same location (station 58461 in Shanghai) during the study period to analyze the relationship between the LLJs and precipitation.

\subsection{Criteria for identifying $L L J S$}

Previous statistical studies have adopted various criteria for identifying LLJs. For the Great Plains of the United States, Bonner (1968) introduced a LLJ classification method by defining threshold values for the maximum wind speed, the maximum height of maximum wind, and the required vertical shear magnitude above the jet. These criteria have been widely used (with small changes in the threshold values) in literature (Mitchell et al. 1995; Whiteman et al. 1997).

In East Asia, a set of criteria suitable for LLJs over Taiwan, in addition to some specific criteria (wind direction, horizontal shear), also included the height of maximum wind, the threshold values for maximum wind, and the vertical shear below wind maximum (Chen and Yu 1988; Chen et al. 1994). The vertical shear above the wind maximum was also adopted as a criterion (Chen et al. 2005). In addition, Pham et al. (2008) applied criteria that were similar to Bonner's (1968) for LLJ detection over Okinawa.

Over mainland China, however, most researchers have identified LLJs simply by horizontal wind speed at specific levels, mainly due to the limitations of data 


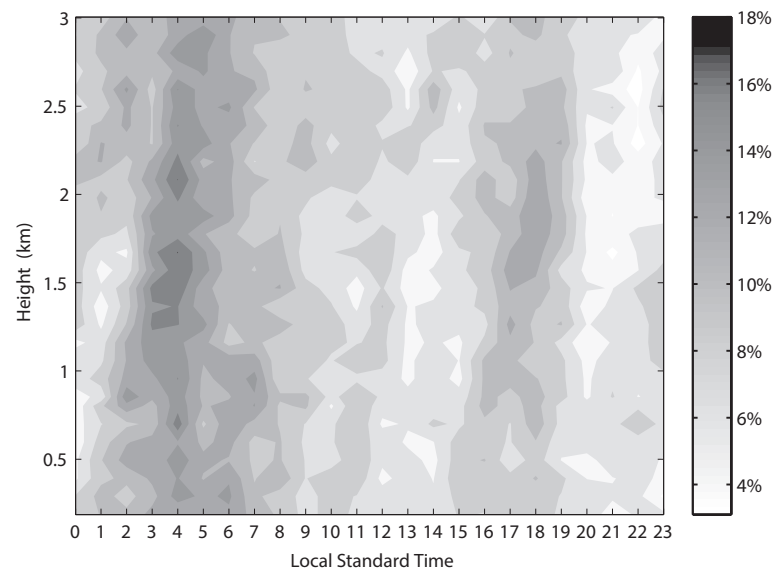

Fig. 2. Time-height Hovmöller diagram of the missing rate for WPR data at Qingpu for the 2-year warm season record.

resolution. Their criteria, that horizontal wind speeds at 925,850 , or $700 \mathrm{hPa}$ levels are equal to or greater than $12 \mathrm{~m} \mathrm{~s}^{-1}$, do not include the requirements of vertical shear of horizontal wind. In this paper, the WPR data allowed us to consider the vertical shear of horizontal wind for identifying LLJs in Shanghai. We adopted the Whiteman criteria (Whiteman et al. 1997), that (1) the maximum wind speed is more than $10 \mathrm{~m} \mathrm{~s}^{-1}$ in the lowest $3 \mathrm{~km}$ and (2) the wind speed must decrease by at least $5 \mathrm{~m} \mathrm{~s}^{-1}$ from the height of the wind maximum to the wind minimum below a height of $3 \mathrm{~km}$ or to a height of $3 \mathrm{~km}$ when no minimum is found. The criteria require LLJs to have a significant vertical shear of horizontal wind, which ensures they have jet-like profiles. The criteria are relatively weak for maximum wind speed, in order to provide a larger number of LLJ samples and higher statistical significance. We defined the height of LLJs as the height of the maximum horizontal wind speed maxima when LLJs occur. The LLJ direction is defined as the wind direction at the height of the LLJ.

\section{Vertical distribution of LLJ occurrence frequency}

The vertical distribution of the occurrence frequency of LLJs is shown in Fig. 3. LLJs occur throughout the $0-3 \mathrm{~km}$ levels, but they occur most frequently at preferred levels. Two peaks are evident in the occurrence frequency profile: one at 500-800 $\mathrm{m}$ and another at $2100-2200 \mathrm{~m}$.

Previous reports of LLJs over the Great Plains of the United States did not quite agree on LLJ altitude, likely because of different vertical resolutions of the

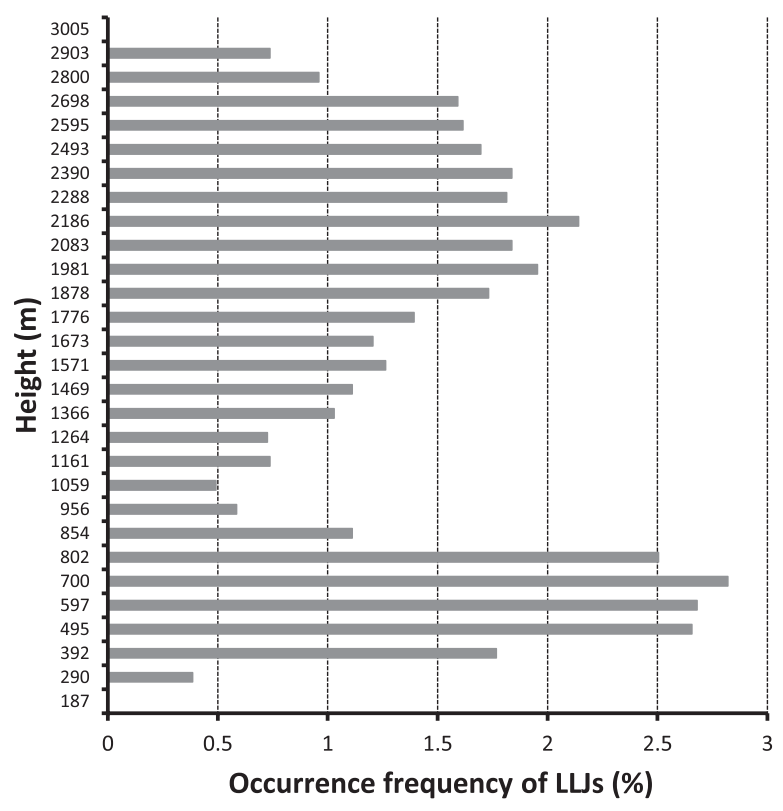

Fig. 3. Vertical profile of the occurrence frequency of LLJs for the 2-year warm season record.

data used. Bonner (1968), using 22 sounding observations, proposed that the mean altitude of LLJs was about 580-1020 $\mathrm{m}$ above ground level (AGL), whereas Whiteman et al. (1997) suggested that southerly LLJs are most frequently found at 300-600 m AGL with higher vertical resolution rawinsonde data. These LLJs over the US Great Plains showed obvious diurnal variations and occurred within the planetary boundary layer (below $1000 \mathrm{~m} \mathrm{AGL).} \mathrm{Our} \mathrm{observations} \mathrm{indicate}$ that LLJs in Shanghai are not limited to the planetary boundary layer. Further evidence from observations of LLJs over East Asia also supports such vertically stratified LLJ distributions. The occurrence frequency of LLJs over the Okinawa Island during the Meiyu periods displayed a double-peak in the vertical: one peak around $500-700 \mathrm{~m}$ and another around $1100-1300 \mathrm{~m}$ (Pham et al. 2008). The double-peak vertical structure of LLJ occurrence frequency over Shanghai in Fig. 3 is consistent with the finding of Pham et al. (2008), except for the more elevated second peak (around 2100-2200 m). With the aforementioned classification of LLJs according to their altitude, we believe that the two peaks could be associated with BLJs and SLLJs, respectively. Therefore, we classified LLJs in Shanghai by their occurrence height: BLJs (below $1000 \mathrm{~m}$ ) and SLLJs (above $1000 \mathrm{~m}$ and below $3000 \mathrm{~m}$ ).

These two types of LLJs in Shanghai show different characteristics in sub-seasonal and diurnal variations in 
occurrence frequency, direction distribution, and relationship with precipitation. These characteristics are described in detail in the next section.

\section{Characteristics of LLJs}

\subsection{Variation in LLJ occurrence frequency \\ a. Sub-seasonal variations}

Figure 4 shows the occurrence frequency of BLJs and SLLJs during the pre-Meiyu, Meiyu, and postMeiyu periods. SLLJs occur more frequently in the Meiyu periods than in the pre- and post-Meiyu periods, whereas BLJs do not display such sub-seasonal variations.

One possible explanation for the higher incidence of SLLJs during the Meiyu periods is the increased activity of synoptic- and sub-synopticscale weather systems during these periods. Previous studies suggested that LLJs over East Asia are closely related to the development of the mesoscale convective systems (MCSs) embedded along Meiyu fronts (Akiyama 1973; Chen and Yu 1988). The increase in SLLJs occurrence is a notable feature during the Meiyu period (Matsumoto et al. 1971; Tao and Chen 1987). Pham et al. (2008) showed that stronger LLJs (those with higher maximum wind speed and stronger wind shear) occur more frequently during the Meiyu periods than the post-Meiyu periods over Okinawa. Therefore, the observation-derived occurrence of SLLJ during the Meiyu periods in our statistics generally agrees with those previous studies, particularly that the SLLJ is closely related to the weather system. This possibility will be investigated further in Section 6 .

Unlike SLLJs, the occurrence frequency of BLJs increases throughout the warm seasons. This indicates that there might be less correlation between BLJs and Meiyu frontal activity during the warm seasons. The increase in BLJ occurrence could be explained by the increase in land-ocean thermal differences, which increases the background geostrophic flow resulting in an increased amplitude of inertial oscillation (Blackadar 1957; Holton 1967; Parish and Oolman 2010) (more detailed explanation will be presented in Section 6).

Our results concerning the sub-seasonal variation in LLJs agree with those from Pham et al. (2008), although they only documented higher incidence of the stronger LLJs during Meiyu periods without further explanation. In Fig. 5, we show that SLLJs are generally higher in wind speed than BLJs. Thus a reasonable explanation for higher incidences of stronger LLJs during the Meiyu periods is that most of the stronger LLJs are SLLJs that occur more frequently during the

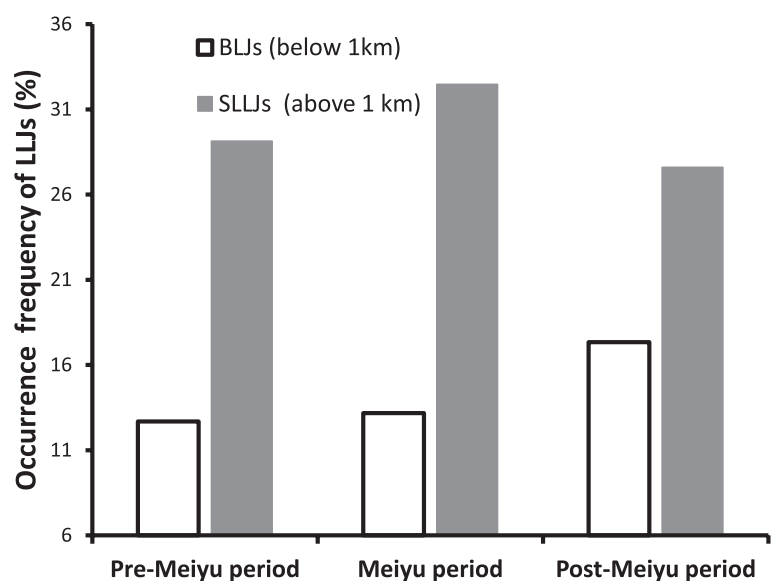

Fig. 4. Occurrence frequency of BLJs (white) and SLLJs (gray) for pre-Meiyu, Meiyu, and post-Meiyu periods.

Meiyu periods.

\section{b. Diurnal variations}

Figure 6 shows the diurnal variations in occurrence frequency of LLJs (including BLJs and SLLJs) in Shanghai. BLJs seem to display more pronounced diurnal variations than SLLJs, with maximum occurrence frequency in nighttime and early morning. The statistical significance of the diurnal cycle of each type of LLJs was tested after Bell and Reid (1993). Using a multiple linear superposition method, the diurnal cycle of occurrence frequency can be approximated as

$$
F(t) \approx f_{0}+c \cos (\omega t)+s \sin (\omega t)
$$

Where represents the daily mean occurrence frequency, $\omega=2 \pi(24 \mathrm{~h})^{-1}$, and $t=0,1,2 \ldots, 23 \mathrm{~h}$. We performed linear regression on the observed occurrence frequency to derive coefficients ( $c$ and $s$ ) for the BLJs and SLLJs, respectively. The goodness of fit of linear regression $\left(R^{2}\right)$ is defined as

$$
R^{2}=1-\frac{S S_{\text {reg }}}{S S_{\text {tot }}}
$$

Where $S S_{\text {reg }}$ and $S S_{\text {tot }}$ are the regression and total variance, respectively. The results from linear regression showed that both BLJs and SLLJs displayed diurnal cycles (significant at the 95\% confidence level). However, the diurnal cycle of the BLJs $\left(R^{2}=0.8717\right)$ was clearer than that of the SLLJs $\left(R^{2}=0.6600\right)$ from a statistical perspective.

The diurnal variation in the LLJ occurrence frequency over the US Great Plains has been studied extensively (Bonner 1968; Mitchell et al. 1995), and the 


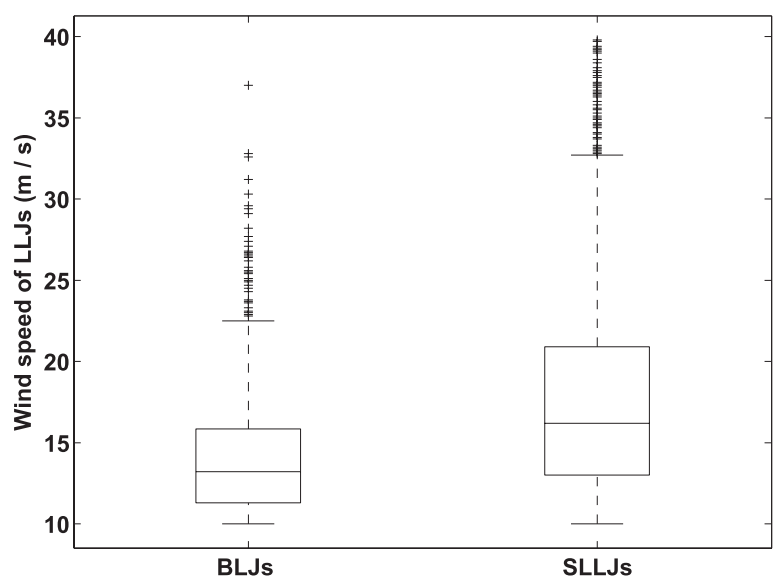

Fig. 5. Box-whisker graph of wind speed for BLJs and SLLJs for the 2-year warm season record. Boxplot shows median and interquartile range, and whiskers indicate the range.

LLJs over Okinawa showed the same diurnal variation (Pham et al. 2008). The diurnal cycle of LLJs (BLJs) is associated with boundary layer processes (Blackadar 1957). Douglas et al. (1998) proposed from observations of low-level wind at Puerto Peñasco that the diurnal cycle of low-level wind is limited below 1800 m AGL, and its amplitude decreases with increasing height. In the previous section, we showed that the BLJ occurrence frequency increases throughout the warm seasons probably because of the increasing amplitude of inertial oscillations in the boundary layer. This idea is also supported by the fact that BLJs occur near the ground with larger thermal contrast in coastal regions. They hence exhibit more pronounced diurnal variation than SLLJs.

\subsection{Distribution of LLJ directions}

The distributions of BLJ and SLLJ wind direction during the warm seasons of 2008 and 2009 are shown in Fig. 7. The SLLJs have mostly southwesterly and westerly winds, whereas the BLJs have mostly southerly winds. The BLJs during the Meiyu periods have more southwesterly components than those during the pre- and post-Meiyu periods.

The difference between the BLJ and SLLJ wind directions could be attributed to their different formation mechanisms. During the warm seasons, southwesterly and westerly low-level wind (at an 1 3 km height) was dominant due to the prevailing monsoon circulation. Thus, the SLLJs that are associated with the synoptic monsoon circulation are mostly southwester-

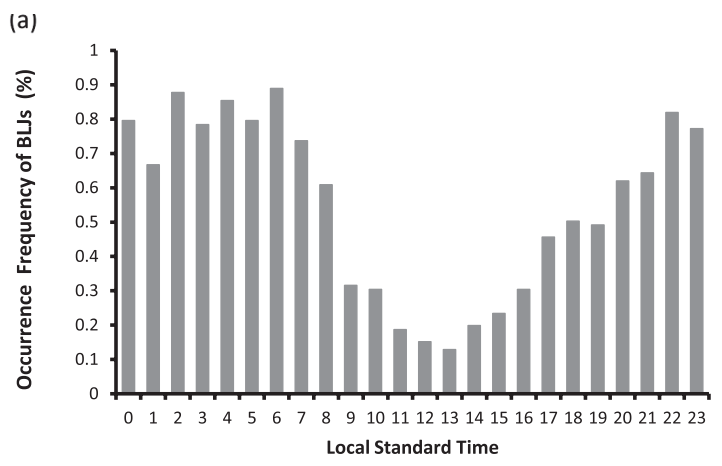

(b)

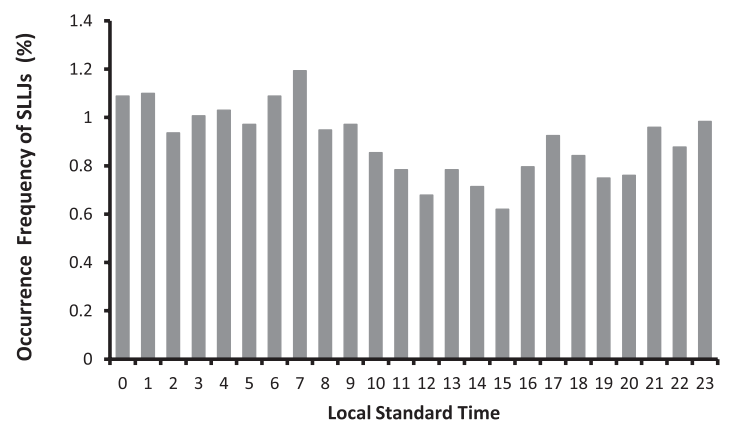

Fig. 6. Diurnal variations in the occurrence frequency of BLJs (a) and SLLJs (b).

lies and westerlies. Chen et al. (2005) adopted a set of criteria suitable for LLJs (SLLJs) over northern Taiwan to identify their occurrence, with an additional requirement of direction of maximum wind (LLJ's direction) between $180^{\circ}$ and $270^{\circ}$ (southwest). On the other hand, BLJs that tend to be parallel to the coastline (southerly in Shanghai) are the result of enhanced summertime mean geostrophic flow along the coastal area in a south-north direction due to the thermal difference between the ocean and land (see Section 6 for details). During the Meiyu periods, the quasi-stationary Meiyu front occurs frequently and could extend lower to influence the BLJs, which leads BLJs have extra southwesterly and westerly wind components during the Meiyu periods.

\subsection{Relationship between LLJs and precipitation}

To study the relationship between LLJs and precipitation, we stratified the observation into rainy and non-rainy periods and performed a composite analysis. Since the missing rate of WPR data is high during heavy rainfall events, causing underestimation of the number of LLJs when heavy rainfall events occur, 
Pre-Meiyu period

BLJs

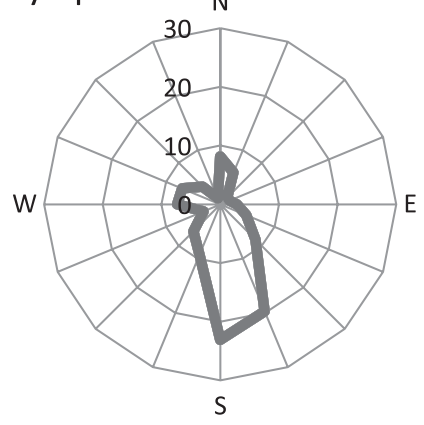

Meiyu period

BLJs

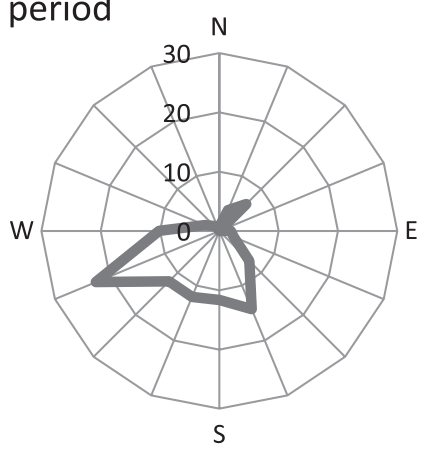

Post-Meiyu period

BLJs

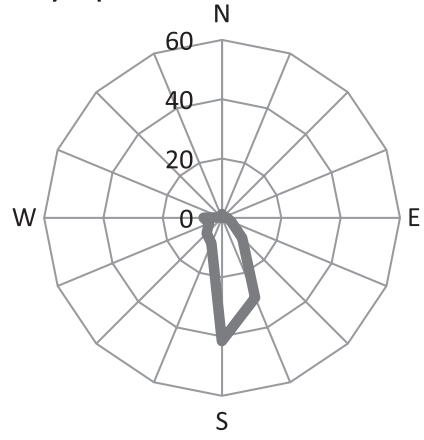

warm season

BLJs

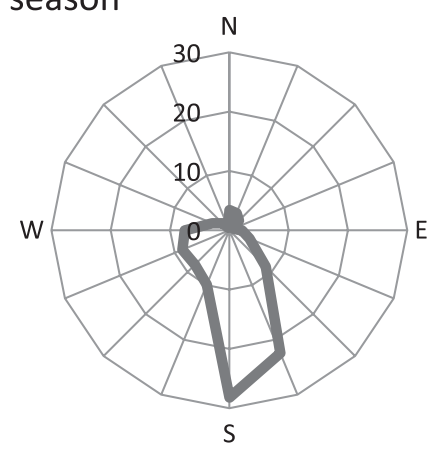

Pre-Meiyu period

SLLJS

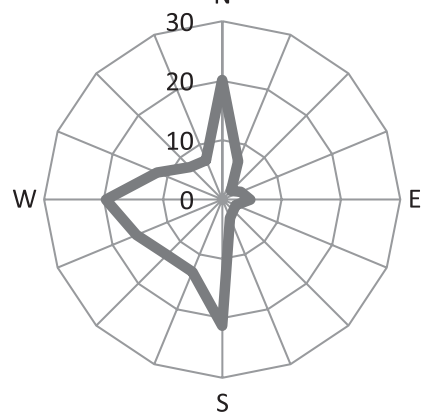

Meiyu period

SLLJS

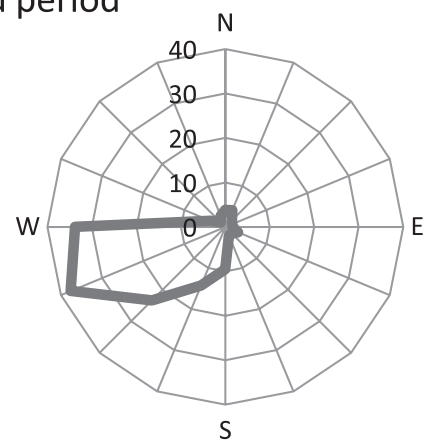

\section{Post-Meiyu period}

SLLJs
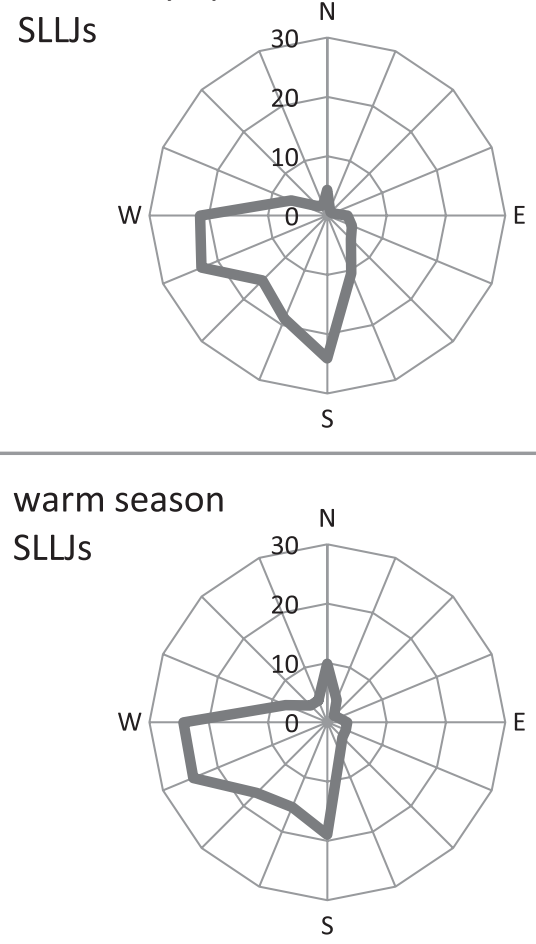

Fig. 7. Frequency distributions of BLJ and SLLJ directions for the warm seasons and the pre-Meiyu, Meiyu and post-Meiyu periods of the 2-year record. 
we defined a rainy day (rainy case) as a day (case) with daily (4-hourly) accumulated rainfall at Qingpu equal to or greater than $1 \mathrm{~mm}$ and less than $10 \mathrm{~mm}$. A pre-rainy (post-rainy) case was defined as a 4-hour case before (after) the corresponding rainy case. In our study, there were 26 rainy days and 57 rainy cases, respectively.

In Fig. 8, we compared the occurrence frequency of BLJs and SLLJs for rainy days and non-rainy days during the warm seasons. Both BLJs and SLLJs occur more frequently on rainy days than on non-rainy days. Compared to BLJs at 500-1000 m height and SLLJs, however, BLJs below a $500 \mathrm{~m}$ height do not have such difference in occurrence on rainy and non-rainy days.

More precisely, we also compared the vertical distribution of LLJ occurrence for pre-rainy, rainy, and postrainy cases with total cases during the warm seasons (Fig 9). BLJs, especially located within a 500 1000 $\mathrm{m}$ height, occur more frequently in pre-rainy, rainy, and post-rainy cases compared to the total cases. The occurrence frequency of SLLJs near a $1500 \mathrm{~m}$ height increases in the rainy and post-rainy cases compared with pre-rainy cases, whereas in post-rainy cases, SLLJs near a $2100 \mathrm{~m}$ height are obviously higher compared to the total cases.

According to the statistical results, SLLJs tend to occur more often during and after rainy cases, whereas BLJs within a 500 1000 m height occur more often throughout rainfall events, including pre-rainy, rainy, and post-rainy cases. However, there seem to be no links between BLJs below a $500 \mathrm{~m}$ height and precipitation.

\section{Relationship between BLJs and SLLJs}

The statistical results from previous sections suggest that there might be some links between BLJs and SLLJs. Therefore, in this section, the simultaneous occurrence frequency for BLJs and SLLJs (double LLJs) were investigated to study the relationship between them. We found that the simultaneous occurrence frequency (the occurrence frequency of double LLJs) is $4.42 \%$ for the warm seasons, while the occurrence frequencies of BLJs and SLLJs are $13.14 \%$ and $21.66 \%$, respectively. When SLLJs occur, the relative occurrence frequency of BLJs is $20.37 \%$; and the relative occurrence frequency of SLLJs is $33.57 \%$ when BLJs occur. This suggests that there is some relation between SLLJ and BLJ occurrences.

Furthermore, like BLJs, double LLJs exhibit pronounced diurnal variation with maxima in nighttime and early morning (Fig. 10a) and occur increasingly throughout the warm seasons (Fig. 11). Double

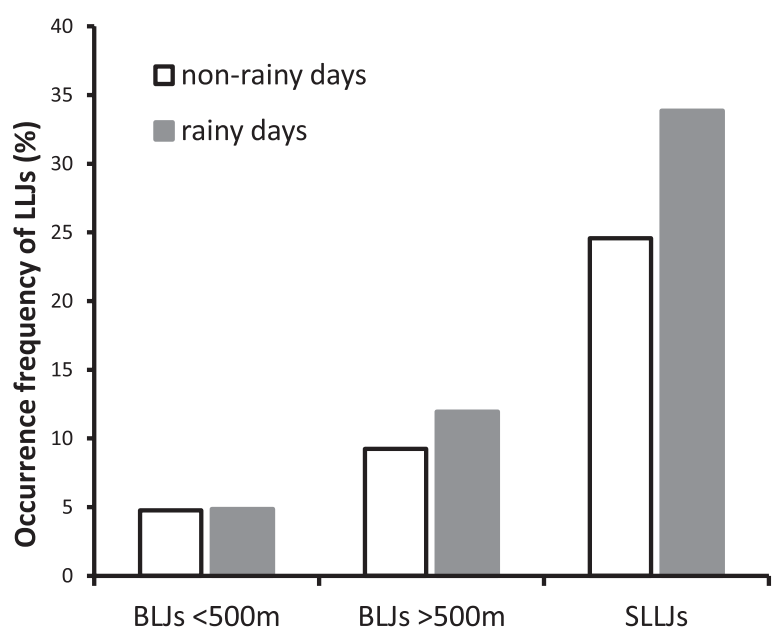

Fig. 8. Occurrence frequency of BLJs below $500 \mathrm{~m}$ and within 500 1000 $\mathrm{m}$ and SLLJs for rainy days and non-rainy days during the warm seasons.

LLJs also occur slightly more frequently on rainy days $(5.78 \%)$ than on non-rainy days $(4.13 \%)$. Kato (1998) suggested, based on numerical simulations of a heavy rainfall event observed in southern Kyushu, western Japan, that increased horizontal momentum in the low layer is transported upward through convective activity to intensify the LLJ (SLLJ). This study indicates that BLJs may affect SLLJs on rainy days. Our statistical results reveal that the double LLJs have the same characteristics as BLJs, which might support the idea of Kato (1998) statistically.

When the lower branch of the double LLJs occurs below a $500 \mathrm{~m}$ height, the frequency of the double LLJs on rainy days $(1.38 \%)$ is not higher than on non-rainy days $(1.66 \%)$. In contrast, when the lower branch of the double LLJs occurs between $500 \mathrm{~m}$ and $1000 \mathrm{~m}$, the frequency of the double LLJs on rainy days $(4.40 \%)$ is slightly higher than on non-rainy days $(2.47 \%)$. This finding indicates that BLJs within a 500 1000m height tend to be associated with SLLJs on rainy days.

We notice that SLLJs not accompanying the BLJs do not exhibit significant diurnal variations (Fig. 10b) with a confidence level $(94.6 \%)$ lower than $95 \%$. Therefore, the slight diurnal variation in the SLLJs is due to the impact of BLJs through the double LLJ cases.

\section{Discussion}

As described in Section 4, BLJs and SLLJs in Shanghai exhibit different statistical characteristics, suggesting that they may experience difference formation processes. 

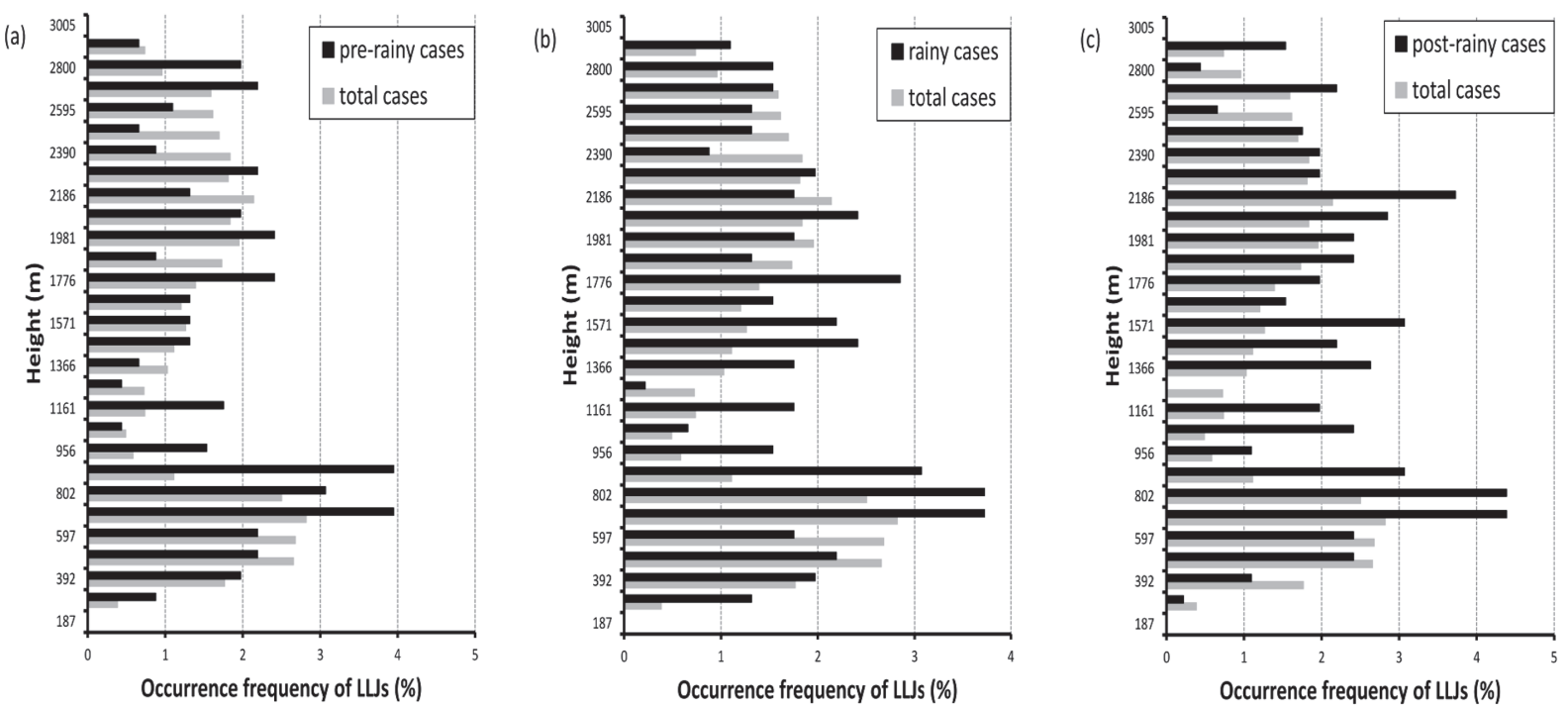

Fig. 9. Vertical structure of LLJs for pre-rainy (a, black), rainy (b, black), post-rainy (c, black), and total cases (gray, $\mathrm{a}, \mathrm{b}$, and $\mathrm{c})$.

Several formation mechanisms for SLLJs over East Asia have been presented in the literature. Earlier literature hypothesized that the LLJ (SLLJ) is a result of downward momentum transport due to convection (Matsumoto et al. 1971; Ninomoya and Akiyama 1974) however, this mechanism cannot explain the formation of localized maximum of wind speed and the direction change of wind between the upper- and low-level jets (Chen et al. 1994). Next, synoptic-scale forcing has been proposed as a possible mechanism for the formation of the LLJ (SLLJ) over East Asia (Chen and $\mathrm{Pu}$ 1985; Tao and Chen 1987; Chen et al. 1994; Chen and Chen 1985). Chen and Pu (1985) suggested that synoptic-scale forcing of the strong migratory high over East China through pressure gradient increase accounts for the formation of LLJs (SLLJs). The development of LLJ (SLLJ) is closely related to the development of lee cyclone to the east of the Tibetan Plateau (Chen et al. 1994; Chen and Chen 1995). The pressure gradient force produced by mesolow (convection-induced low) can also enhance LLJ (SLLJ) that is located on the south side of the mesolow, causing feedback between convection and the strengthening LLJ (SLLJ) (Kato 1998; Davison 1998; Zhang et al. 2003; Lai et al. 2011). In addition, the effect of latent heat release may contribute for the development of LLJs under synoptic forcing (Chen 1982; Chou et al. 1990). Chou et al. (1990), through a two-dimensional simulation, suggested that coriolis acceleration of the northward motion in the lower branch of the mesoscale secondary circulation induced by convective latent heat release can lead to LLJ (SLLJ) development. Our statistical results and these mechanisms together suggest that SLLJs in Shanghai might be closely related to synoptic and sub-synoptic weather systems, and that precipitation with convection and latent heat release favors the development of SLLJs in Shanghai under suitable weather systems. SLLJs occurrence frequency increased cohesively with enhanced precipitation (Subsection 4.3), as well as increased Meiyu frontal activity during the Meiyu periods (Sub-subsection 4.1.a). Furthermore, Kato et al. (2007) suggested that SLLJs associated with the Meiyu front around a height of $3 \mathrm{~km}$ stabilize the atmosphere because they bring warm air. Thus SLLJs near $2000 \mathrm{~m}$ may play an adverse role in strengthening precipitation, so that they tend to occur more frequently during post-rainy cases.

BLJs at different locations may form due to different mechanisms. BLJs were found over the northwestern Taiwan coast during the early summer rainy season as a result of orographic blocking of the SLLJs by the island terrain ( $\mathrm{Li}$ and Chen 1998), where they displayed diurnal variation with a maximum in the early morning (Lin et al. 2011). The formation of LLJs over the Great Plains (BLJs) is due to inertial oscillations (Blackadar 1957) and shallow baroclinicity produced by the sloping terrain (Holton 1967). The characteristics of BLJs in Shanghai include the diurnal variation of 
(a)

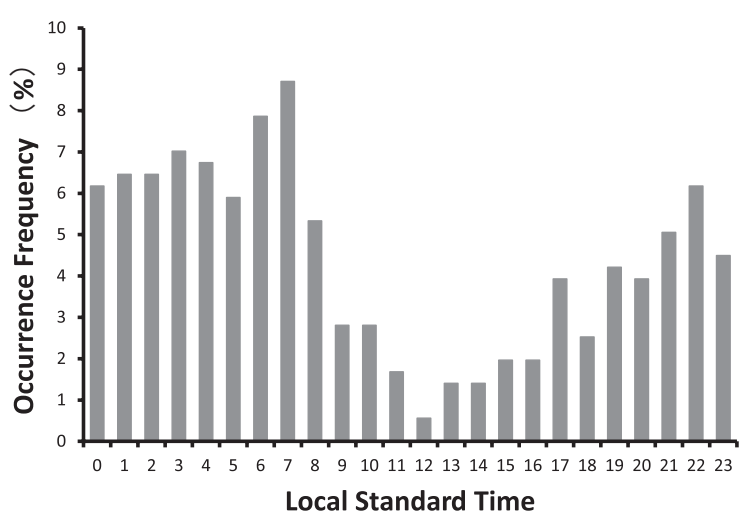

(b)

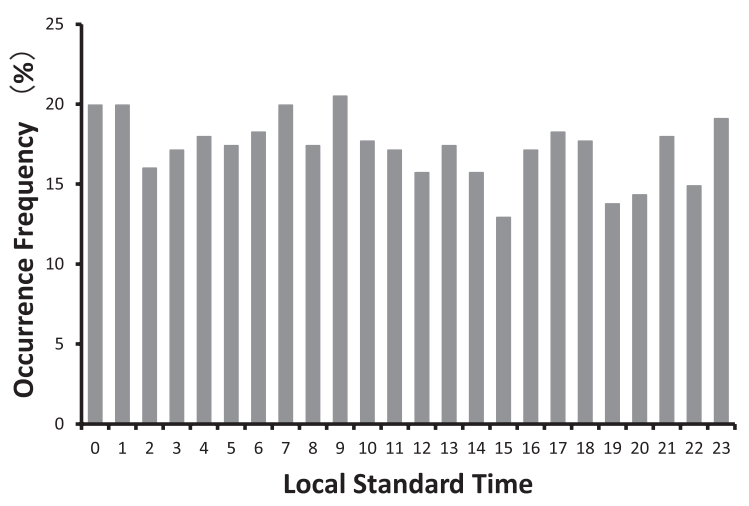

Fig. 10. Diurnal variations in the occurrence frequency of double LLJs (a) and SLLJs with double LLJs cases removed (b) during the warm seasons.

occurrence frequency with a maximum in nighttime and early morning (Fig. 6), and a clockwise rotation of the southerly wind maximum (BLJs tend to be southerly, see Subsection 4.2) during the night (Fig. 12). Considering the flat terrain of Shanghai, orographic blocking is not considered as a possible mechanism for BLJs in Shanghai. On the basis of the clockwise rotation of the southerly wind maximum, the inertial oscillation mechanism described by Blackadar (1957) is plausible for the nighttime BLJ maximum in Shanghai. Song et al. (2005) also suggested that the southerly Great Plains LLJs (BLJs) demonstrate veering similar to that expected from inertial oscillations with clear clockwise rotation of the wind.

In addition to inertial oscillation mechanisms, the thermal difference between land and ocean also plays a significant role in formation of BLJs over Shanghai.

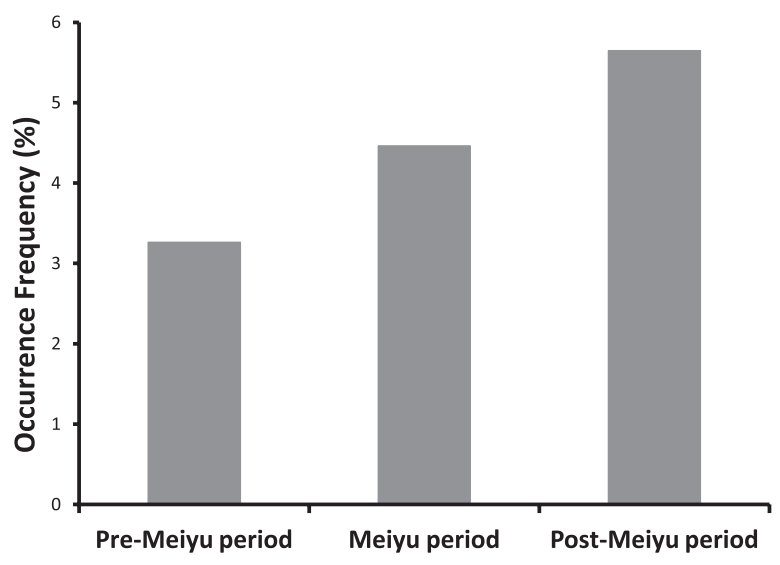

Fig. 11. Occurrence frequency of double LLJs in the pre-Meiyu, Meiyu, and post-Meiyu periods.

During the warm seasons, the thermal difference in coastal terrain, where the geopotential height gradient at $925 \mathrm{hPa}$ (the lower peak occurs at around $925 \mathrm{hPa}$ ) is large (Fig. 13a), enhances the low-level background geostrophic wind associated with the northwest Pacific subtropical high. The maximum geostrophic wind is found during the late afternoon due to the diurnal thermal difference. The pattern of geopotential height anomaly and zonal temperature anomaly at 12 UTC (20 LST in the late afternoon) based on the FNL analysis is shown in Fig. 13b. The increase in the pressure gradient increases the southerly geostrophic wind component. Even though the actual low-level wind remains fairly weak, the ageostrophic wind has increased by late afternoon (around 20 LST). Once night sets in, the boundary layer height/turbulent exchange decreases significantly and the ageostrophic processes discussed by Blackadar (1957) commence, which enhances the development of the LLJ nighttime maximum, although the nighttime cooling of land decreases the geostrophic flow. The strongest pressure gradient (land-sea thermal) in late afternoon helps set the stage for the inertial oscillation. Therefore, the coastal terrain is also responsible for the nighttime BLJ maximum in Shanghai, and the BLJs tend to be southerly during the warm seasons.

Similarly, for the maximum occurrence of the summertime LLJs (BLJs) over the US Great Plains during the night, both inertial oscillation suggested by Blackadar (1957) and diurnal heating and cooling of the terrain slopes suggested by Holton (1967) are thought to be important (Jiang et al. 2007; Parish and Oolman 2010). The land-sea thermal contrast along the coastal area in China is similar to the thermal contrast due to sloping terrain near Great Plains in US. 


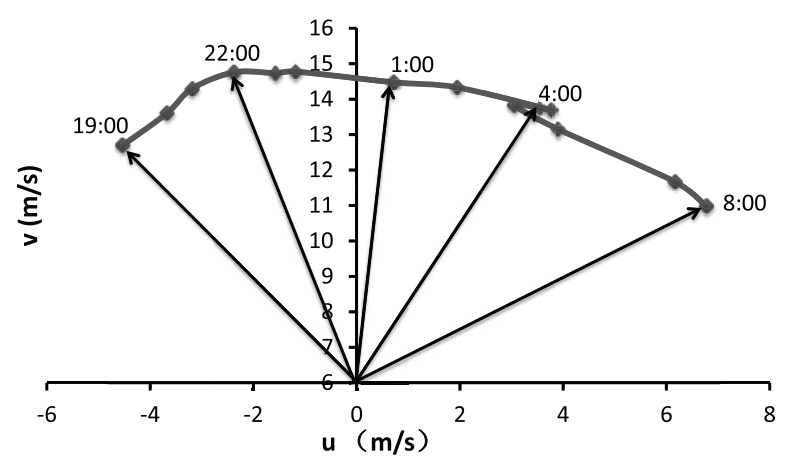

Fig. 12. Nocturnal variations (1900-0800 LST) in the southerly LLJ hodograph for wind components averaged at the Qingpu site for the 2-yr dataset. A three-point moving average was used for each time.

Rife et al. (2010), using global downscale reanalysis suggested that the direction of BLJs depends strongly on the geographic orientation of the adjacent terrain and the underlying horizontal heat contrasts. Zhang et al. (2006), using a sensitivity simulation, showed that eliminating the surface heat fluxes (Blackdar effect) and land-sea contrast produces an impact on the development of the LLJ over the Mid-Atlantic State, with its area-averaged intensity reduced from $12 \mathrm{~m} \mathrm{~s}^{-1}$ to about 6 and $10 \mathrm{~m} \mathrm{~s}^{-1}$, respectively.

Of course, BLJs may also be somewhat affected by synoptic weather systems. As shown in Subsection 4.2, during the Meiyu period the quasi-stationary Meiyu front occurs frequently and extends lower to pose an extra impact on the BLJs, which leads to believe that BLJs have extra southwesterly and westerly wind components. BLJs within 500-1000 m occur often throughout rainfall events, including pre-rainy, rainy, and post-rainy cases. This suggests that some synoptic weather systems (e.g., the Meiyu front) may somewhat strengthen BLJs within 500-1000 m, which are favorable for precipitation.

In all the above discussion, the formation mechanism of LLJs is based on statistical results for observational data. Further studies of specific cases and numerical models are necessary.

\section{Summary}

In this study, 1289-MHz wind profiler radar (WPR) data with high temporal and vertical resolution were used to compile statistics for $0-3 \mathrm{~km}$ wind profiles at the Qingpu site in Shanghai, China. The characteristics (including temporal variations, wind direction,
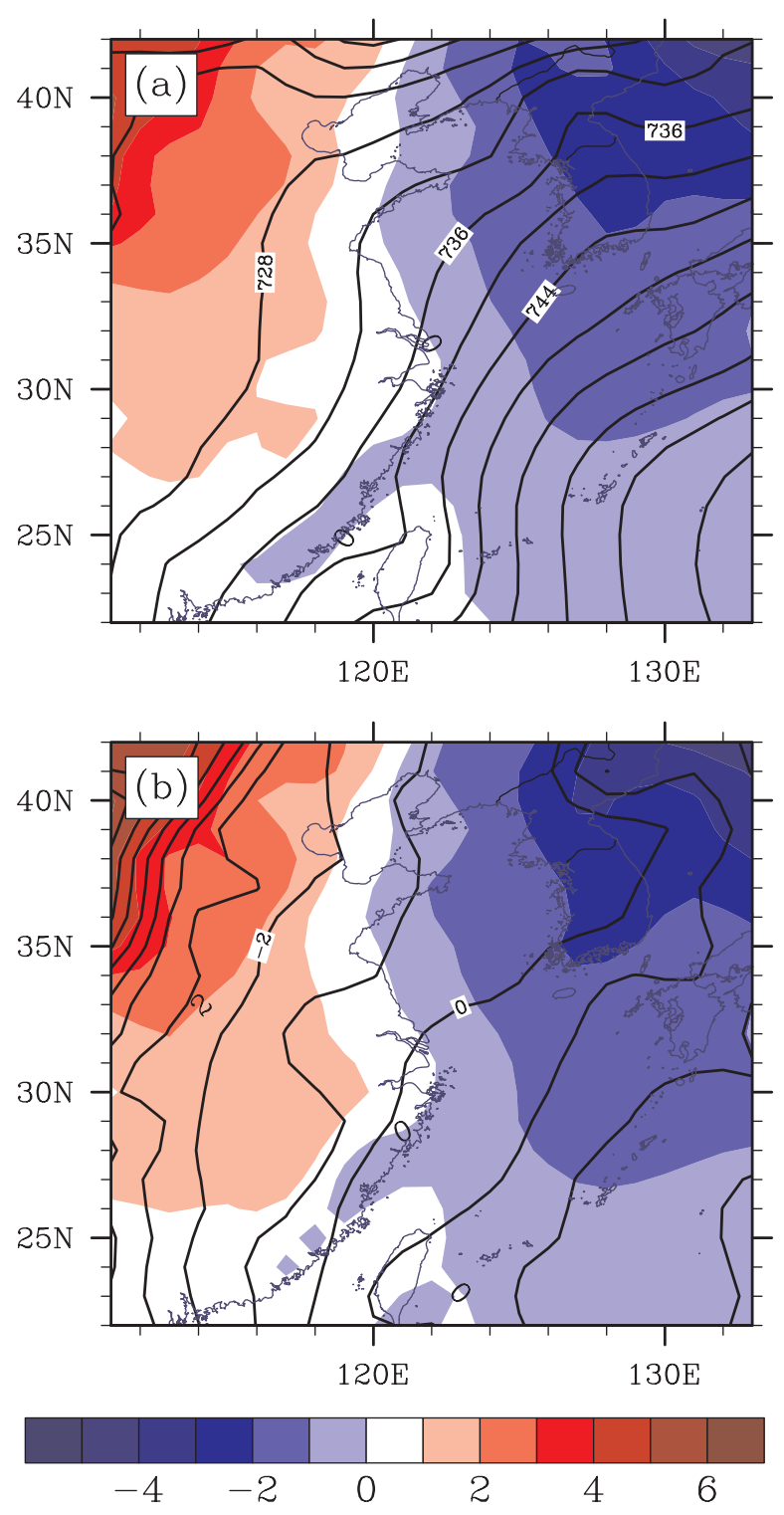

Fig. 13. Pattern of $925-\mathrm{hPa}$ geopotential height [contours (gpm)] and temperature anomaly [shading (K)] (a) and geopotential height anomaly and zonal temperature anomaly at 12:00 UTC (b) averaged over the warm seasons.

and relationship with precipitation) of LLJs during the 2008-2009 warm seasons (pre-Meiyu, Meiyu, and post-Meiyu periods) were evaluated.

Statistics showed that LLJs occur more frequently at $500-800 \mathrm{~m}$ and $2100-2200 \mathrm{~m}$ in the vertical. On the basis of this double-peak vertical distribution of occurrence frequency and previous work (Chen et al. 1994), we classified the LLJs into two types: boundary layer 
jets (BLJs, below $1000 \mathrm{~m}$ ) and synoptic-scale-system-related LLJs (SLLJs, above $1000 \mathrm{~m}$ and below $3000 \mathrm{~m}$ ). The different characteristics between BLJs and SLLJs, as well as the possible explanation for such differences, are summarized as follows.

1. SLLJs occur more frequently during the Meiyu periods than non-Meiyu periods, whereas the occurrence frequency of BLJs increases throughout the warm seasons with no peak during the Meiyu periods. The enhanced Meiyu frontal activity is the important ingredient of the formation of SLLJs, and thus SLLJ incidence increases with frontal activity during Meiyu periods. BLJs, though show some correlation with the Meiyu front, are more related to boundary layer processes.

2. Both BLJs and SLLJs display diurnal cycles with maxima in nighttime and early morning. Because the thermal difference and inertial oscillation that drive the diurnal cycle decrease with height, SLLJs at higher altitude are less sensitive to the thermal difference and boundary layer processes (inertial oscillation) than are BLJs. Hence, SLLJs exhibit a weaker diurnal cycle than BLJs. Additionally, SLLJs not accompanying the BLJs do not exhibit diurnal variation.

3. Embedded in the southwesterly monsoon circulation during the warm season, SLLJs are mostly southwesterly and westerly winds, while BLJs are mostly southerly winds because of the strong summertime southerly geostrophic flow over coastal terrain due to the west-east land-ocean temperature gradient.

4. Both BLJs and SLLJs display some correlation with precipitation. However, BLJs below $500 \mathrm{~m}$ are poorly correlated with precipitation. SLLJs tend to occur often during and after rainfall cases, whereas BLJs tend to occur frequently throughout rainfall process including pre-rainy, rainy, and post-rainy cases.

5. There is a link between BLJs and SLLJs. Double LLJs (simultaneous occurrence for BLJs and SLLJs) show the same characteristics as BLJs, such as pronounced diurnal variation and high occurrence frequency in the post-Meiyu periods. The double LLJs for which the lower branch occurs at 500-1000 m occur more slightly often on rainy days than on non-rainy days.

This study is based on analysis of data from only one station. The results should be further verified by analyses of data from other stations in East Asia. The formation mechanisms of SLLJs and BLJs in Shanghai also require further study using numerical models.

\section{Acknowledgements}

This study is supported by Chinese 973 program 2013CB430104, National Science Foundation under Grants 40921160380 and 41275048, and Science and Technology Commission of Shanghai under Grants 10dz0581300. We thank the editor and two anonymous reviewers for their valuable comments in improving the original manuscript.

\section{References}

Akiyama, T., 1973: The large-scale aspects of the characteristic features of the Baiu front. Pap. Meteor. Geophys, 24, 157-188.

Bell, T. L., and N. Reid, 1993: Detecting the diurnal cycle of rainfall using satellite observations. J. Appl. Meteor., 32, 311-322.

Blackadar, A. K., 1957: Boundary layer wind maxima and their significance for the growth of nocturnal inversions. Bull. Amer. Meteor. Soc, 38, 283-290.

Bonner, W. D., 1968: Climatology of the low level jet. Mon. Wea. Rev, 96, 833-850.

Burk, S. D., and W. T. Thompson, 1996: The summertime low-level jet and marine boundary layer structure along the California coast. Mon. Wea. Rev, 124, 668-686.

Chen, G. T.-J., C.-C. Wang, and D. T.-W. Lin, 2005: Characteristics of low-level jets over northern Taiwan in Mei-Yu Season and their relationship to heavy rain events. Mon. Wea. Rev, 133, 20-43.

Chen, G. T. J., and C. C. Yu, 1988: Study of low-level jet and extremely heavy rainfall over northern Taiwan in the Mei-Yu season. Mon. Wea. Rev, 116, 884-891.

Chen,G. T. J., and C. P. Pu, 1985: A case study of the formation of a low-level jet over subtropical China and heavy precipitation in northern Taiwan. Atmos. Sci, 12, 23-32. (in Chinese with English abstract.)

Chen, Q., 1982: The instability of the gravity-inertia wave and its relation to low-level jet and heavy rainfall. $J$. Meteor. Soc. Japan, 60, 1041-1057.

Chen, X.-A., and Y.-L. Chen, 1995: Development of low-level jets during TAMEX. Mon. Wea. Rev., 123, 1695-1719.

Chen, Y.-L., X. A. Chen, and Y.-X. Zhang, 1994: A diagnostic study of the low-level jet during TAMEX IOP 5. Mon. Wea. Rev, 122.

Chou, L. C., C. P. Chang, and R. Williams, 1990: A numerical simulation of the Mei-Yu front and the associated low level jet. Mon. Wea. Rev, 118, 1408-1428.

Davison, N. E., K. Kurihara, T. Kato, G. Mills, and K. Puri, 1998: Dynamics and prediction of a mesoscale extreme rain event in the baiu front over Kyushu, Japan. Mon. Wea. Rev., 126, 1608-1629.

Djuric, D., and M. Damiani, 1980: On the formation of the low-level jet over Texas. Mon. Wea. Rev, 108, 1854 1865. 
Douglas, M. W., A. Valdez-Manzanilla, and R. Garcia Cueto, 1998: Diurnal variation and horizontal extent of the low-level jet over the northern gulf of California. Mon. Wea. Rev, 126, 2017-2025.

Frisch, A. S., B. W. Orr, and B. E. Martner, 1992: Doppler radar observations of the development of a boundary-layer nocturnal jet. Mon. Wea. Rev, 120, 3-16.

Holton, J. R., 1967: The diurnal boundary layer wind oscillation above sloping terrain1. Tellus, 19, 199-205.

Jiang, X., N. C. Lau, I. M. Held, and J. J. Ploshay, 2007: Mechanisms of the Great Plains low-level jet as simulated in an AGCM. J. Atmos. Sci., 64, 532-547.

Karipot, A., M. Y. Leclerc, and G. Zhang, 2009: Characteristics of nocturnal low-level jets observed in the north Florida area. Mon. Wea. Rev, 137, 2605-2621.

Kato, T., 1998: Numerical simulation of the band-shaped torrential rain observed over southern Kyushu, Japan on 1 August 1993. J. Meteor. Soc. Japan, 76, 97-128.

Kato, T., S. Hayashi, and M. Yoshizaki, 2007: Statistical study on cloud top heights of cumulonimbi thermodynamically estimated from objective analysis data during the Baiu season. J. Meteor. Soc. Japan, 85, 529-557.

Lai, H. W., C. A. Davis, and B. J. Jou, 2011: A subtropical oceanic mesoscale convective vortex observed during sowmex/timrex. Mon. Wea. Rev., 139, 2367-2385.

Li, J., and Y. L. Chen, 1998: Barrier jets during TAMEX. Mon. Wea. Rev, 126, 959-971.

Lin, P. L., Y. L. Chen, C. S. Chen, C. L. Liu, and C. Y. Chen, 2011: Numerical experiments investigating the orographic effects on a heavy rainfall event over the northwestern coast of Taiwan during TAMEX IOP 13. Meteor. Atmos. Phys.,114, 1-16.

Lothon, M., F. Saïd, F. Lohou, and B. Campistron, 2008: Observation of the diurnal cycle in the low troposphere of West Africa. Mon. Wea. Rev, 136, 3477-3500.

Matsumoto, S., K. Ninomiya, and S. Yoshizumi, 1971: Characteristic features of Baiu front associated with heavy rainfall. J. Meteor. Soc. Japan, 49, 267-281.

Mitchell, M. J., R. W. Arritt, and K. Labas, 1995: A climatology of the warm season Great Plains low-level jet using wind profiler observations. Wea. Forecasting, 10, 576-591.

Newton, C. W., 1967: Severe convective storms. Vol. 12, Academic Press, 257-303 pp.

Ninomiya, K., and T. Akiyama, 1974: Band structure of mesoscale echo cluster associated with low-level jet stream. J. Meteor. Soc. Japan, 52, 300-313.

Ninomiya, K., and T. Murakami, 1987: The early summer rainy season (Baiu) over Japan. Oxford Univ. Press, 93-121 pp.

Parish, T. R., and L. D. Oolman, 2010: On the role of sloping terrain in the forcing of the Great Plains low-level jet. J. Atmos. Sci., 67, 2690-2699.

Parish, T. R., A. R. Rodi, and R. D. Clark, 1988: A case study of the summertime Great Plains low level jet. Mon. Wea. Rev, 116, 94-105.

Pham, N. T., K. Nakamura, F. A. Furuzawa, and S. Satoh, 2008: Characteristics of low level jets over Okinawa in the Baiu and post-Baiu seasons revealed by wind profiler observations. J. Meteor. Soc. Japan, 86, 699-717.

Rife, D. L., J. O. Pinto, A. J. Monaghan, C. A. Davis, and J. R. Hannan, 2010: Global distribution and characteristics of diurnally varying low-level jets. J. Climate, 23, 5041-5064.

Song, J., K. Liao, R. L. Coulter, and B. M. Lesht, 2005: Climatology of the low-level jet at the Southern Great Plains atmospheric boundary layer experiments site. $J$. Appl. Meteor., 44, 1593-1606.

Stensrud, D. J., 1996: Importance of low-level jets to climate: A Review. J. Climate, 9, 1698-1711.

Tao, S., and L. Chen, 1987: A review of recent research on the East Asian summer monsoon in China. Vol. 60, Oxford University, 60-92 pp.

Uccellini, L. W., and D. R. Johnson, 1979: The coupling of upper and lower tropospheric jet streaks and implications for the development of severe convective storms. Mon. Wea. Rev, 107, 682-703.

Uccellini, L. W., R. A. Petersen, K. Brill, P. Kocin, and J. J. Tuccillo, 1987: Synergistic interactions between an upper-level jet streak and diabatic processes that influence the development of a low-jevel jet and a secondary coastal cyclone. Mon. Wea. Rev, 115, 22272261.

Van de Wiel, B. J. H., A. Moene, G. Steeneveld, P. Baas, F. Bosveld, and A. Holtslag, 2010: A conceptual view on inertial oscillations and nocturnal low-level jets. $J$. Atmos. Sci., 67, 2679-2689.

Werth, D., and Coauthors, 2011: The simulation of the southern Great Plains nocturnal boundary layer and the low-level jet with a high-resolution meso-scale atmospheric model. J. Appl. Meteor. Climatol., 50, 1497-1513.

Whiteman, C. D., X. Bian, and S. Zhong, 1997: Low-level jet climatology from enhanced rawinsonde observations at a site in the southern Great Plains. J. Appl. Meteor, 36, 1363-1376.

Zhang, D. L., S. Zhang, and S. J. Weaver, 2006: Low-level jets over the mid-Atlantic states: Warm-season climatology and a case study. J. Appl. Meteor. Climatol., 45, 194-209.

Zhang, Q. H., K. H. Lau, Y. H. Kuo, and S. J. Chen, 2003: A numerical study of a mesoscale convective system over the Taiwan Strait. Mon. Wea. Rev., 131, 11501170.

Zhong, S., J. D. Fast, and X. Bian, 1996: A case study of the great plains low-level jet using wind profiler network data and a high-resolution mesoscale model. Mon. Wea. Rev, 124, 785-806. 